East African Medical Journal Vol. 86 No. 4 April 2009

CIGARETTE SMOKING AND ORAL HEALTH AMONG HEALTHCARE STUDENTS

P. Komu, BDS (Nbi), Ministry of Health, P. O. Box 30016 - 00100, Nairobi, Kenya, E. A. O. Dimba, BDS (Nbi), PhD, (Bergen), F. G. Macigo, BDS, MPH, PGD - STI (Nbi), Depatment of Oral and Maxillofacial Surgery, Oral Pathology and Oral Medicine, School of Dental Sciences, University of Nairobi, P. O. Box 19676 - 00202, Nairobi, Kenya and A. E. O. Ogwell, BDS, MPH (Nbi), MPhil (Bergen), Ministry of Health, P. O. Box 30016 - 00100, Nairobi, Kenya

Request for reprints to: Dr. E. A. O. Dimba, Department of Oral and Maxillofacial Surgery, Oral Pathology and Oral Medicine, School of Dental Sciences, University of Nairobi, P. O. Box 19676 - 00202, Nairobi, Kenya

\title{
CIGARETTE SMOKING AND ORAL HEALTH AMONG HEALTHCARE STUDENTS
}

\author{
P. KOMU, E. A. O. DIMBA, F. G. MACIGO and A. E. O. OGWELL
}

\begin{abstract}
Background: The knowledge, attitudes and practices of cigarette smoking and health risks among health workers has been found to be predictive of their efficiency as agents for tobacco cessation campaigns.

Objective: To describe the knowledge, attitudes and practices of cigarette smoking and oral health risks among healthcare professional students.

Design: A cross sectional multi-level study.

Setting: College of Health Sciences, University of Nairobi.

Subjects: Two hundred and eighty one students.

Results: Thirty four $(12.1 \%)$ of the students were current smokers, $174(61.95 \%)$ had never smoked, while $73(26 \%)$ were former smokers. Seventy nine point four per cent of the current smokers were males and $\mathbf{2 0 . 6 \%}$ were females. Pharmacy students had the highest smoking prevalence at $11(32.4 \%)$, while dental and nursing students had the lowest percentages of current smokers. Differences observed in smoking status of students in the constituent schools of the College of Health Sciences were statistically significant $(p=0.008)$. Apart from knowledge levels on the association between tobacco consumption and lung cancer $(p=$ 0.142), there were statistically significant differences in the awareness of the severe oral and systemic effects of smoking amongst the four student groups.

Conclusions: There is a need for harmonisation of teaching of oral and systemic effects of smoking so as to impact on the smoking habits and effectiveness of healthcare professional students as agents of smoking cessation programmes.
\end{abstract}

\section{INTRODUCTION}

Smoking is a major cause of morbidity and mortality with approximately four million smokers dying per year from smoking related diseases $(1,2)$. Among men in industrialised countries, smoking is estimated to be the cause of $40-45 \%$ of all cancer deaths, $90-95 \%$ of lung, over $85 \%$ of oral, $75 \%$ of chronic obstructive lung disease, and $35 \%$ of cardiovascular disease deaths in those aged thirty five to sixty nine years (3). Approximately $50 \%$ of smokers are killed by their habit and mortality due to conditions associated with tobacco use may increase to ten million by the year $2030(4,5)$.

Oral and dental effects of smoking include staining of teeth, reduction of ability to smell and taste, melanosis, smoker's palate, oral candidiasis and dental caries (6). Smoking also increases the severity of periodontal disease and has an adverse effect on almost all forms of periodontal therapy (7). Tobacco is also by far the most important risk factor for oral cancer and precancer $(1,8)$. Smoking among pregnant women may cause complications resulting in spontaneous abortion, premature deliveries, low birth weight and perinatal mortality. The magnitude of risk for developing tobacco associated diseases is related to the quantities consumed as well as the amounts of tar and nicotine present in the tobacco products; nicotine being the main agent responsible for addiction to tobacco (9). Despite the health risks involved, many health professionals continue to smoke (10).

Research indicates that healthcare providers play a significant role in helping smokers to quit (11). However, physicians who smoke tend to underestimate the health hazards associated with smoking compared to their nonsmoking counterparts may not be as effective 
in counselling patients to quit smoking (12). Therefore, only those healthcare professionals who are seen to have internalised anti-smoking principles will have the most positive effect on their patients (13-15). It is suggested that if the smoking prevalence among healthcare providers declined below that of the general population, then the smoking prevalence of the general population would also decline (10). However, current data on smoking among healthcare professional students indicate that they smoke at the same rate as the general population (16).

Attitudes to smoking and the awareness of the specific health risks of tobacco have been identified as important influences on smoking habits (17). Global studies on smoking trends among students undergoing professional education in healthcare, however, indicate that some of these students either begin or continue to smoke during their studies $(18,19)$. The purpose of this study was, therefore, to describe the knowledge, attitudes and practices of cigarette smoking and oral health risks among health care professional students at the University of Nairobi.

\section{MATERIALS AND METHODS}

The study was conducted at the University of Nairobi, College of Health Sciences, which offers undergraduate degree programmes in medicine, dental surgery, pharmacy and nursing. The various levels of study include levels 1 to 5 for the medical students and levels 1-4 for the dental, pharmacy and nursing students. Selection was done by means of stratified random sampling of students within the clinical years of training. Data were collected using self administered questionnaires which recorded the demographic characteristics of the students, class year, smoking habits, attitude towards training on smoking cessation and knowledge on oral and systemic effects of smoking. The data were analysed using SPSS (Version 12.0) statistical computer software.

\section{RESULTS}

Cigarette consumption in the College of Health Sciences, University of Nairobi: The response rate was $93.67 \%$, with 281 out of 300 questionnaires having been returned. Of these, $170(60.4 \%)$ were filled by male students and $111(39.6 \%)$ by female students. Analysis of the respondents according to the level of study revealed that $171(61.2 \%)$ were in their third year of study; $36(12.8 \%)$ were in the fourth year and $73(26 \%)$ were in the fifth year. Most of the students $174(61.9 \%)$ had never smoked, $34(12.1 \%)$ were current smokers and $73(26 \%)$ were former smokers who had quit for a variety of reasons (Table 1). Pearson's chisquare test showed that the differences observed in smoking status of students in the constituent schools of the College of Health Sciences were statistically significant $(\mathrm{p}=0.008)$.

Of the current smokers, six $(18.2 \%)$ had smoked for less than one year, $20(60.6 \%)$ for lone to five years, six $(18.2 \%)$ for six to ten years and one student had smoked for over ten years. Daily cigarette use was the norm among the current smokers with only five students (16.1\%) consuming less than one stick a day. The majority $17(54.8 \%)$ of current smokers consumed one to five cigarettes per day; eight (25.8\%) smoked six to ten cigarettes per day and five $(16.1 \%)$ consumed 11 to 15 cigarettes per day. Filter cigarettes appeared to have been the most popular, with $28(87.3 \%)$ of smokers using them exclusively. Only three smokers smoked non-filter cigarettes exclusively while one smoker reported using both types. Twenty $(62.5 \%)$ of the current smokers started smoking before joining the university. The rest $12(37.5 \%)$ started smoking after joining the university. The age at which smokers first tried the habit varied from 5 to 24 years of age (Figure 1). When questioned about attempting to quit, 21 $(63.6 \%)$ of smokers reported having tried to stop the habit while $12(36.4 \%)$ said that they had not tried to quit.

Table 1

Distribution of smokers, non-smokers and students with a history of smoking

\begin{tabular}{|c|c|c|c|c|c|c|c|}
\hline \multirow{3}{*}{ Smoking status } & \multirow[b]{2}{*}{ Dental sciences } & \multicolumn{6}{|c|}{ Frequencies by professional discipline } \\
\hline & & Medicine & Nur & sing & Phat & macy & Total \\
\hline & No. $(\%)$ & No. $(\%)$ & No. & $(\%)$ & No. & $(\%)$ & No. $(\%)$ \\
\hline Current smoker & $\begin{array}{ll}3 & 8.8\end{array}$ & 17 & 3 & 8.8 & 11 & 32.4 & $34 \quad 12.10$ \\
\hline Never smoked & $23 \quad 13.2$ & $115 \quad 66.1$ & 13 & 7.5 & 23 & 7.5 & $174 \quad 61.92$ \\
\hline Quit smoking & $\begin{array}{ll}1 & 1.4\end{array}$ & 67.1 & 4 & 5.5 & 19 & 5.5 & $\begin{array}{ll}73 \quad 25.98\end{array}$ \\
\hline Total & 9.6 & $181 \quad 64.4$ & 20 & 7.1 & 53 & 18.9 & 281 \\
\hline
\end{tabular}


Figure 1

Age at first trial of smoking for students

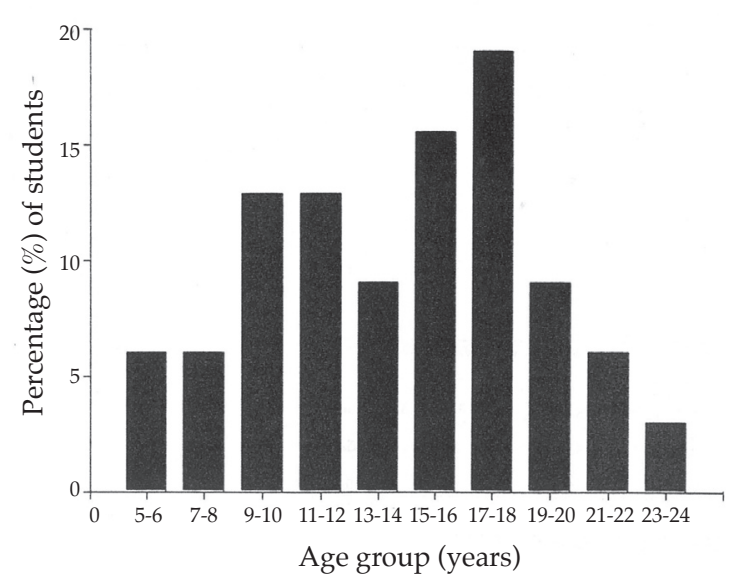

Knowledge on the adverse effects of smoking among healthcare professional students: Apart from knowledge levels on the association between lung cancer and tobacco consumption, there were statistically significant differences in the awareness of systemic effects of smoking amongst the four student groups (Table 2). Moreover, on assessment of the oral effects of smoking, differences in the students' awareness of diseases of the mouth associated with smoking was statistically significant in severe conditions such as oral cancer (Table 3). The majority of students $242(85 \%)$ reported to have obtained their information from their educational curricula and the media. Thirty nine (15\%) of the students also cited other sources of information which included cultural teachings, public seminars, personal observations, peers, family, church and the internet. Most of the students 276 (96\%) believed that cessation of smoking does reduce the risk of developing oral and systemic diseases associated with smoking. However, $11(4 \%)$ thought that cessation would have no effect on risk reduction. Two hundred and seventy eight $(99.6 \%)$ students generally thought that smoking led to addiction. One student was not sure of this fact and one previous smoker who had quit the habit stated that smoking was not addictive.

Table 2

Comparison of knowledge of systemic effects of smoking among students

\begin{tabular}{|c|c|c|c|c|c|c|}
\hline \multirow[t]{2}{*}{ Systemic effects of smoking } & \multicolumn{4}{|c|}{ Frequencies by professional discipline } & \multicolumn{2}{|c|}{ Total Frequencies } \\
\hline & No. $(\%)$ & No $(\%)$ & No. $(\%)$ & No. $(\%)$ & No $(\%)$ & P-values* \\
\hline Lung cancer & 27100 & 17998.9 & 1995 & 5094.3 & 27597.9 & 0.142 \\
\hline Chronic obstructive lung disease & 2696.3 & 16993.4 & 1890 & 3973.6 & 25289.7 & 0.000 \\
\hline Upper aero-digestive tract cancer & 2592.6 & 17596.7 & 1890 & 4075.5 & 25891.8 & 0.002 \\
\hline Coronary heart disease & 2281.5 & 17194.5 & 1260 & 3769.8 & 24286.1 & 0.000 \\
\hline Hypertension & 2281.5 & 16691.8 & 1365 & 3667.9 & 23784.3 & 0.000 \\
\hline Peptic ulcers & 1140.7 & 16189.0 & 1155 & 2649.1 & 20974.4 & 0.000 \\
\hline Spontaneous abortions & 1140.7 & 13574.6 & 1155 & 2547.5 & 18264.8 & 0.000 \\
\hline Low birth weights & 2281.5 & 16691.7 & 1890 & 3871.7 & 24486.8 & 0.002 \\
\hline
\end{tabular}

*Pearson's chi-square test (where $\mathrm{P}<0.05$ is considered statistically significant)

Table 3

Comparison of knowledge of oral effects of smoking among students

\begin{tabular}{|c|c|c|c|c|c|c|}
\hline $\begin{array}{l}\text { Oral effects of } \\
\text { smoking }\end{array}$ & $\begin{array}{l}\text { Freque } \\
\text { ental sciences } \\
\text { No. }(\%)\end{array}$ & $\begin{array}{c}\text { ncies by pro } \\
\text { Medicine } \\
\text { No. }(\%)\end{array}$ & $\begin{array}{l}\text { essional di } \\
\text { Nursing } \\
\text { No. }(\%)\end{array}$ & $\begin{array}{l}\text { cipline } \\
\text { Pharmacy } \\
\text { No. }(\%)\end{array}$ & $\begin{array}{c}\text { Total } \\
\text { frequencies } \mathrm{f} \\
\text { No. }(\%)\end{array}$ & $\begin{array}{l}\text { P- value } \\
\text { or college }\end{array}$ \\
\hline Oral candidiasis & 1244.4 & $48 \quad 26.5$ & 525.0 & 1222.6 & $77 \quad 27.4$ & 0.089 \\
\hline Hyper pigmentation & 2385.1 & $134 \quad 74.0$ & 1470 & 3667.9 & 20773.7 & 0.000 \\
\hline Periodontal disease & 2488.9 & 10457.5 & 1260 & 2445.3 & 16458.4 & 0.003 \\
\hline Staining of teeth & 27100 & 17496.1 & 1995 & 4992.5 & 26995.7 & 0.441 \\
\hline Dental caries & 1140.7 & $87 \quad 48.1$ & 1050 & 1630.2 & 12444.1 & 0.200 \\
\hline Oral cancer & 27100 & 14348.1 & 1365 & 3158.5 & 21476.2 & 0.000 \\
\hline
\end{tabular}

*Person's chi-square test, (where $\mathrm{P}<0.05$ is considered statistically significant) 
The students were then asked whether they investigated the smoking habits of their patients and $238(86.2 \%)$ said they did whereas $38(13.8 \%)$ did not. Of those who recorded the smoking habits of their patients, $192(69.8 \%)$ tried to counsel the patients against smoking while $83(30.2 \%)$ did not. Concerning the training of health care professionals on counselling patients against smoking, $140(50.4 \%)$ students felt that their curriculum did not train them adequately for this while $138(49.6 \%)$ students thought that their training was sufficient. In addition, 269 $(96.8 \%)$ of the students said that the training on patient counselling was necessary while only nine $(3.2 \%)$ of the students thought that this was not necessary.

\section{DISCUSSION}

Although healthcare professional students are expected to offer smoking cessation advice to their patients, their own smoking habits frequently affect their health as well as their effectiveness as agents for change in patients' tobacco consumption habits (20-22). Results from this study showed a low smoking prevalence among healthcare professional students of $12.1 \%$, with highest smoking prevalence observed among pharmacy students (Table 1). Notably, the $9.3 \%$ current smoking rates reported by medical students are substantially lower than the $18 \%$ prevalence noted for the same group in 1987 (23) but higher than rates reported in Australia $(4-6 \%)$, China $(6 \%)$, India (7\%), Thailand $(7 \%)$ and the US (7\%) (19). The smoking prevalence among dental students was $11 \%$ which was higher than the decreasing prevalences reported among dental students in the US (4\%), Canada $(3 \%)$ and India (11\%) (18). Nursing students had a smoking rate of $15 \%$ which was comparable to statistics obtained from nursing students in the US which ranged from $15-25 \%$ (24).

This study supports the finding in global research that despite acquiring theoretical information on risk factors associated with tobacco consumption, healthcare professional students begin or continue to smoke during their studies at the university $(19,21)$. Eighty seven point five per cent of the smokers interviewed said that they knew the health effects of smoking before they started smoking and $70.6 \%$ agreed that such knowledge would not have had an effect on their starting the habit. This lack of impact of risk awareness on smoking is consistent with previous studies that have shown that knowledge of health risks does not necessarily act as a deterrent to smoking $(2,15)$. This study reports that the peak age for initiation into the smoking habit for healthcare professional students was 15-18 years of age. The main reasons for starting the habit included peer influence, stress and curiosity. The addictive nature of the smoking habit was demonstrated by the $63.6 \%$ of the current smokers who had attempted to quit without success. Among the former smokers who had quit, health reasons were cited as the main reason for quitting. This was in direct contrast to a number of international studies which ranked the most effective reasons for quitting as request(s) by the smoker's family or a healthcare professional $(11,19)$.

The teaching curricula in the constituent schools of the College of Health Sciences appeared to have a major impact on awareness of the adverse effects of smoking and subsequently on the smoking habits of the students. Pharmacy students, who demonstrated the lowest awareness levels of oral and systemic effects of smoking, had the highest smoking prevalences. Medical students showed the highest levels of competence concerning the systemic effects of smoking, while dental students had high levels of awareness of the oral effects of smoking. The knowledge levels of nursing students on the adverse effects of smoking were comparable to that of pharmacy students in many instances. However, nursing students, who were mainly females, smoked considerably less than the pharmacy students who were $60 \%$ male, perhaps reflecting the cultural taboos surrounding tobacco consumption among women in the society $(18,19)$. The expressed need for further training on tobacco counselling in the entire student body was consistent with previous studies conducted in various parts of the world (25-27).

Results from this study must be interpreted in light of the limitations of a self reporting survey design. These include the difficulties in using standardised international methodologies for assessing tobacco use $(18,19)$. It is possible that under-reporting of severity of this addiction may have occurred because of negative associations with the habit (28). Also, although the study maintained strict anonymity of the respondents, female students needed some reassurance before they agreed to participate. The data, however, showed a clear need for integration of training efforts in the process of equipping healthcare professional students to act as agents for tobacco cessation.

\section{ACKNOWLEDGEMENTS}

This research was conducted as a collaborative effort between the Departments of Periodontology, Community and Preventive Dentistry and Oral and Maxillofacial Surgery, Oral Pathology and Medicine at the School of Dental Sciences, University of Nairobi and the Division of Non-Communicable Diseases at the Ministry of Health. 


\section{REFERENCES}

1. Petersen, P. E. The World Oral Health Report 2003 - Continuous improvement of oral health in the $21^{\text {st }}$ century - the approach of the WHO Global Health Programme. Comm. Dent. Oral Epidem. 2003; 31 (Suppl 1): 3 - 24.

2. Steptoe, A., Wardle, J., Cui, W., et al. An international comparison of tobacco smoking, beliefs and risk awareness in university students from 23 countries. Addiction. 2002; 97: 1561 -1571.

3. Johnson, N. W. Tobacco use and oral cancer - a global perspective. J. Dent. Educ. 2001; 65: 328 - 339.

4. Nagy, K., Barabas, K. and Nari, T. Attitudes of Hungarian health care professional students to tobacco and alcohol. Euro. J. Dent. Educ. 2004; 4: 32-35.

5. Doll, R., Peto, R., Wheatley, K., et al. Mortality in relation to smoking: 40 years' observations on male British doctors. Brit. Med. J. 1994; 309: 901 - 911.

6. Reibel, J. D. Tobacco and oral diseases. Medical Principles and Practice. 2003; 1 (Suppl 12: 22-32.

7. Johnson, G. K. and Slach, N. A. Impact of tobacco use on periodontal status. J. Dent. Educ. 2001; 65: 313 - 321.

8. Sham, A.S., Cheung, L.K., Jin, L.J. and Corbet, E.F. The effects of tobacco use on oral health. Hong Kong Med. J. 2003; 9: 271 - 277.

9. Macigo, F. G. Public health implication of the proposed Kenyan tobacco control bill. Afr. J. Oral Health Sci. 2003; 4: 187 - 188.

10. Puska, P. M. Barrueco, M., Roussos, C., Hider, A. and Hogue, S. The participation of health professionals in a smoking cessation programme positively influences the smoking cessation advice given to patients. Intern. J. Clin. Prac. 2005; 59: 447 - 452.

11. US Department of Health and Human Services. Reducing tobacco use: a report of the Surgeon General, Atlanta, GA: US Department of Health and Human Services, CDC; 2000.

12. Lancaster, T., Stread, L., Silagy, C., et al. Effectiveness of interventions to help people stop smoking: findings from the Cochrane Library. Brit. Med. J. 2000; 321: 355-358.

13. Anderson, P. Managing alcohol problems in general practice. Brit. Med. J. Clin. Res. Eds. 1985; 290: 1873 - 1875.

14. Glynn, T. J. Physicians and smoke free society. Arch. Inter. Med. 1988; 148: 1013 -1016.
15. Richmond, R. and Heater, N. General practitioner intervention for smoking cessation: past and future prospects. Behaviour Change. 1990; 7: 110 - 119.

16. Clark, E., McCann, T. V., Rowe, K. and Lazenbatt A. Cognitive dissonance and undergraduate nursing students' knowledge of and attitude about smoking. J. Adv. Nurs. 2004; 46: 586 - 594.

17. Richmond R. Teaching medical students about tobacco. Thorax. 1999; 54: 70- 78.

18. Smith, D.R., Legat, P. A. An international review of tobacco smoking among dental students in 19 countries. Inter. Dent. J. 2007; 57: 452 - 458.

19. Smith, D. R. and Legat, P.A. An international review of tobacco smoking among medical students. J. Postgraduate Med. 53: 55 - 62.

20. Chapman, S. Doctors who smoke. Brit. Med. J. 1995; 311: 142 - 143

21. Nagy, G., Blazek, J. and Banoczy, J. The smoking habits of dentists and dental students in Hungary: of Hungarian Dent. (Special issue) 2002; 24 - 29.

22. Jenkins, K. and Ahijevych, K. Nursing students' beliefs about smoking, their own smoking behaviours, and use of professional tobacco treatment intervention. Applied Nurs. Res. 2003 ; 16: 164- 172.

23. Lore, W. Smoking habits in Kenya. A preliminary study involving University of Nairobi Medical Students. East Afr. Med. J. 1987; 64: 248- 252.

24. Ashwin, A. P., Hill, K., Balras, V., et al. A comparison of smoking habits among medical and nursing students. CHEST. 2003; 124: 1415 -1420.

25. Poychonopoulou, A., Gatou, T. and Athanassouli, T. Greek dental students attitude towards tobacco control programmes. Intern. Dent. J. 2004; 54: 119125.

26. Giacona, M. B. Tobacco cessation within the dental curriculum in the US and internationally. NY State Dent. J. 2004; 70: 40 - 43.

27. Jarvis, M. J., Wardle, J., Waller, J. and Owen, L. Prevalences of hardcore smoking in England and associated attitudes and beliefs. Brit. Med. J. 2003; 326: $1061-1063$.

28. Tomori, M., Zalar, B., Kores Plesnicar, B., et al. Smoking in relation to psychosocial risk factors in adolescents. European Child and Adol Psych. 2006; 10: $143-150$. 